\begin{tabular}{|c|ccc|c|}
\hline & PORT SAID ENGINEERING RESEARCH JOURNAL \\
\hline
\end{tabular}

\title{
Adapting the Green Pyramid Rating System for Assessing Zero Energy Concept on Neighborhoods Level
}

\author{
Mostafa Mohamed Abd El-Hafeez ${ }^{1}$, Ashraf El-Mokadem ${ }^{2}$, Islam Sallam ${ }^{3}$ and Basma Nashaat El-Mowafy ${ }^{4}$
}

\begin{abstract}
Countries face challenges in changing their risky and costly systems of fossil fuel usage into sustainable development. So many communities started using Neighborhood sustainability assessment tools since the turn of $21^{\text {st }}$ century. Countries utilize these tools to measure their success in approaching sustainable development goals. Each tool is accommodated to suite its environment. For example, Leadership in Energy and Environmental Design (LEED)Rating System is concerned on energy and gives lower value to water while Green Pyramid Rating System (GPRS) does exactly the opposite. On the other hand there isn't a comprehensive neighborhoodrating system in Egypt. This paper proposed a Green Pyramid Neighborhood Rating System, which is based on the original GPRS to assess zero energy concepts on neighborhood level counting building, infrastructure, street network, sidewalks, facilities and community development. This rating system can help architects in designing sustainable communities by defining the weight of every category and point.
\end{abstract}

Keywords: Neighborhood sustainability assessment tools, GPRS, LEED, Zero Energy Community, Rating System, Neighborhood Development, Sustainable Design, Energy Management, GPNRS.

\section{INTRODUCTION}

The sustainable design concept is a way to reinvent communities to provide citizens energy needs with minimal environmental impact. Assessment tools help in achieving this concept by evaluating sustainable buildings and communities. There are many assessment tools focusing on the urban and regional level, as well as the level of the single building. On the other hand there is a lack of attention and experience on the intermed iate level of urban neighborhoods. But no single city can contribute to overall sustainability if its own component parts are not sustainable [1]. The reset of this paper is organized as follows;overview of neighborhood sustainability assessment tools in Section 2, secondGreen Pyramid Rating System for buildings is presented in Section 3. Then, leadership in energy and environmental design building certification system is shown in Section 4. Comparison between weights of categories in LEED and GPRS is summarized in Section 5. In Section 6, proposed Green Pyramid Neighborhood Rating System is discussed to evaluate sustainable neighborhood in Egypt. Finally; results and discussions are concluded in Section 7.

\section{OVERVIEW OF NEIGHBORHOOD SUSTAINABILITY ASSESSMENT TOOLS}

\footnotetext{
${ }^{T}$ Professor at Department of Architectural Engineering and Urban Planning, Faculty of Engineering, Port Said University.

${ }^{2}$ Professor and Head of Department of Architectural Engineering and Urban Planning, Faculty of Engineering, Port Said University

3Lecture at Architectural Engineering and Uban Planning Department, Faculty of Engineering, Port Said University.

${ }^{4}$ Demonstrator at Department of Architectural Engineering and Urban Planning, Faculty of Engineering, Port Said University
}

Neighborhood Sustainability Assessment (NSA)tool is a tool that evaluates and rates the performanceof a given neighborhood against a set of standards, tomeasure the neighborhoods' success in approaching sustainability goals[1]. There are many assessment tools for urban communities like CASBEE for Urban Developmentfrom Japan, BREEAM Communities fromUnited Kingdom, and LEED forNeighborhood Development from USA[2]. But Egypt has only a building assessment tool; which is GPRS without a Neighborhood Sustainability Assessment tool. This paper presented LEED and GPRS for buildings and compared between them .Then a proposed assessment tool is presented to evaluate sustainable neighborhoods in Egypt.

\section{GREEN PYRAMID RATING SYSTEM}

The Green Pyramid Rating System (GPRS) is anEgyptian environmental rating system for buildings. It evaluates environmental credentials of buildings and rates the buildings themselves. It includes 6 categories with a bonus to Innovation and Added Value category:

1. Sustainable Site

2. Energy Efficiency

3. Water Efficiency

4. Materials and Resources

5. Indoor Environmental Quality

6. Management

The weights of categories are shown in Figure 1. 


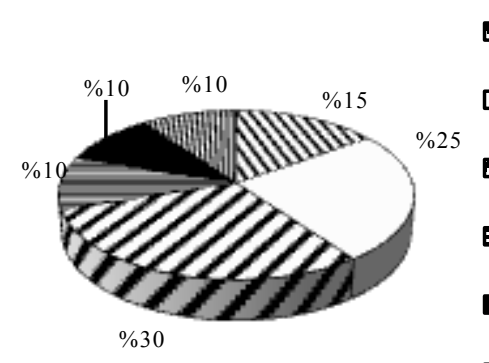

$\mathbf{\Delta}$ Sustainable Site

$\square$ Energy Efficiency

- Water Efficiency

曰 Materials And

Resources

Indoor Environmental

m Management Quality

Figure 1:3. Green Pyramid Rating Systemcategories weight.

\section{LEADERSHIP IN ENERGY AND ENVIRONMENTAL DESIGN BUILDING CERTIFICATION SYSTEM}

Leadership in Energy and Environmental Design (LEED) is developed by the United States Green Building Council in 2000. It is a tool for all types and sizes of buildings. LEED-ND p laces emphas is on the site selection, design, and construction elements that bring buildings and infrastructure together into a neighborhoodand relate the neighborhood to its landscape as well as its local and regional context [1]. It includes 7 categories:
1. Sustainable Sites
2. Water Efficiency
3. Energy and Atmosphere
4. Materials and Resources
5. Indoor Environmental Quality
6. Regional Priority
7. Innovation in Design

The weights of categories are shown is shown in Figure 2.

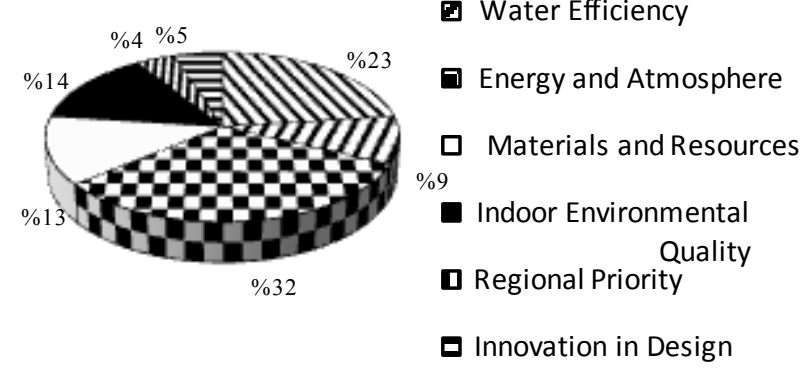

Figure 2:4. Leadership In Energy And Environmental Designcategories weight.

\section{COMPARISON BETWEEN WEIGHTS OF CATEGORIES IN LEED AND GPRS}

As shown in previous discuss LEED and GPRS give different weightand priority to every category as shown in Table 1. The priorities of categories arestaged in four phases:

- High priority (From 40\%-30\%).
- Medium priority (From 30\%-20\%).

- Low priority (From 20\%-10\%).

- No priority (Under $10 \%$ ).

Table 1: The priority of every categ ory in the two systems

\begin{tabular}{|c|c|c|c|c|}
\hline \multirow{2}{*}{ Categories } & \multicolumn{2}{|c|}{ LEED } & \multicolumn{2}{|c|}{ GPRS } \\
\hline & Percentage & priority & Percentage & priority \\
\hline Sustainable Sites & $23 \%$ & Medium & $15 \%$ & Medium \\
\hline Wat er Efficiency & $9 \%$ & Low & $30 \%$ & High \\
\hline $\begin{array}{ll}\text { Energy } & \text { and } \\
\text { Atmosphere } & \\
\end{array}$ & $32 \%$ & High & $25 \%$ & Medium \\
\hline \begin{tabular}{|ll} 
Materials and \\
Resources
\end{tabular} & $13 \%$ & Low & $10 \%$ & Low \\
\hline $\begin{array}{l}\text { Indoor } \\
\text { Environmental } \\
\text { Quality }\end{array}$ & $14 \%$ & Low & $10 \%$ & Low \\
\hline $\begin{array}{l}\text { Innovation in } \\
\text { Design }\end{array}$ & $5 \%$ & Low & $0 \%$ & No \\
\hline RegionalPriority & $4 \%$ & Low & $0 \%$ & No \\
\hline Management & 0 & No & $10 \%$ & Low \\
\hline
\end{tabular}

FromTable 1, it is concluded that:

- Because of the Egyptian water problem; GPRS gives the main priority to water efficiency after that comes energy category to face energy resources depletion. Also it gives priority to sustainable sites to reduce environment impacts.

- In the other hand, LEED gives the maximum weight to energy category. After that come sustainable sites, indoor environmental quality and materials categories.

Based on those building rating systems, the proposed rating system is developed as presented in next section.

\section{PROPOSED GREEN PYRAMID NEIGHBORHOODRATING SYSTEM}

The proposed rating system is a tool for evaluating sustainable neighborhoods in Egypt. It includes four main categories:
1. Sustainable Site.
2. Neighborhood Pattern.
3. Sustainable Buildings.
4. Management and Innovation.

The details of those categories will be discussed later in next subsections.

This rating system contains 140 points to evaluate any project. Theprojects with less than 40 credits will be classified as 'Uncertified. On the other hand the certificated projects may have one of the rating levels of GPNRS as shown in Table 2.

Table 2: Green Pyramid Neighborhood Rating Levels.

\begin{tabular}{|c|c|}
\hline Required points & $\begin{array}{c}\text { Proposed Py ramid Green } \\
\text { Neighborhood Rating levels }\end{array}$ \\
\hline $40-49$ credits & GPNRS Certified \\
\hline $50-59$ credits & Silver Pyramid \\
\hline $60-79$ credits & Gold Pyramid \\
\hline 80 credits and above & Green Pyramid \\
\hline
\end{tabular}


Now, every category will be presented with its objectives and detailed points. The project must satisfy all the stated Mandatory Minimum Requirements of every category to earn the category points. The checklist of GPNRS with rating points is presented in Table 3.

Table 3: Proposed zero energy neighborhood rating checklist.

\begin{tabular}{|c|c|}
\hline Category & points \\
\hline Sustainable Site & 35 \\
\hline M.1 Site Selection & $\bar{M}$ \\
\hline M.2 Habitat Conservation & $\mathrm{M}$ \\
\hline M.3 Agricultural Land and Water Conservation & $\mathrm{M}$ \\
\hline M.4 Disaster Avoidance & $\mathrm{M}$ \\
\hline 1. Developed Areas & 10 \\
\hline 2. $\quad$ Reduced Automobile Dependence & 10 \\
\hline 3. $\quad$ Bicycle Network & 7 \\
\hline 4. Habitat and Water Conservation & 8 \\
\hline Neighborhood pattern & 57 \\
\hline M.1 Transportation Efficiency & $\bar{M}$ \\
\hline M.2 Compact Development & $\mathrm{M}$ \\
\hline 1. Walkable Streets & 12 \\
\hline 2. $\quad$ Mixed-Income Diverse Communities & 9 \\
\hline 3. $\quad$ Compact Development & 8 \\
\hline 4. Mixed-Use Neighborhood Centers & 5 \\
\hline $\begin{array}{ll}\text { 5. } & \text { Tree-Lined and Shaded Streets }\end{array}$ & 6 \\
\hline 6. Community Outreach and Involvement & 3 \\
\hline $\begin{array}{ll}\text { 7. } & \text { Street Network }\end{array}$ & 5 \\
\hline 8. $\quad$ Access to Civic and Public Spaces & 3 \\
\hline $\begin{array}{ll}\text { 9. } & \text { Reduced Parking Footprint } \\
\end{array}$ & 3 \\
\hline 10. Neighborhood Schools and Play ground & 3 \\
\hline Sustainable Buildings and Infrastructure. & 42 \\
\hline M.1 Certified Green Building & $\bar{M}$ \\
\hline M.2 Minimum Building Energy Efficiency & $\mathrm{M}$ \\
\hline M.3 Minimum Building Water Efficiency & $\mathrm{M}$ \\
\hline M.4 Construction Activity Pollution Prevention & $\mathrm{M}$ \\
\hline \multicolumn{2}{|l|}{ Water $31 \%$} \\
\hline 1. Indoor Water Efficiency improvement & 3 \\
\hline 2. $\quad$ Outer Water Efficiency improvement & 3 \\
\hline 3. Waste Water Management & 7 \\
\hline \multicolumn{2}{|l|}{ Energy $26 \%$} \\
\hline 4. $\quad$ Certified Green Buildings & 4 \\
\hline 5. $\quad$ Energy Efficiency improvement & 1 \\
\hline 6. On-Site Renewable Energy Sources & 2 \\
\hline 7. $\quad$ Infrastructure Energy Efficiency & 1 \\
\hline 8. Neighborhood Heating and Cooling & 1 \\
\hline $\begin{array}{ll}\text { 9. } & \text { Energy Micro grid sy stem }\end{array}$ & 2 \\
\hline \multicolumn{2}{|l|}{$\begin{array}{l}\text { Sustainable site } 14 \% \\
\end{array}$} \\
\hline 10. Solar Orientation & 3 \\
\hline 11. Urban Heat Reduction & 3 \\
\hline \multicolumn{2}{|l|}{ Indoor environmental quality10\% } \\
\hline 12. Optimized Ventilation & 2 \\
\hline 13. Thermal Comfort: & 1 \\
\hline 14. Visual and Acoustic Comfort & 1 \\
\hline \multicolumn{2}{|l|}{ Materials 10\% } \\
\hline 15. Regional and Recycled Materials & 4 \\
\hline \multicolumn{2}{|l|}{ Management 10\% } \\
\hline 16. Solid Waste Management Infrastructure & 2 \\
\hline 17. Minimizing pollution during construction & 1 \\
\hline 18. Respect Historic or Cultural Interest Sites & 1 \\
\hline Innovation and Design Process & 6 \\
\hline Innovation & 3 \\
\hline Cultural Heritage & 3 \\
\hline
\end{tabular}

Each category written in Table 3 is discussed in next subsections with more details.

\subsection{Category 1: Sustainable Site}

\section{A. Objectives}

- Make an improvement and redevelopment in existing and new cities.

- Reduce vehicle trips and vehicle miles traveled (VMT).

- Improve the health of the citizens.

- Protect habitat and agricultural resources.

B. Details of credit points in categ ory 1:

I. Mandatory Minimum Requirements

M.1 Site Selection: Credit points are obtainable to choose a site which is served by existing water and other infrastructures.

M.2 Habitat Conservation: Credit points are obtainable to apply an approved habitat conservation plan.

M.3 Agricultural Land and Water Conservation: Cred it points are obtainable for:

a.The project does not disturb soils and agricultural opportunities .

b.Water bodies is not affected or damaged by new development.

M.4 Disaster Avoidance: Credit points are obtainable to locate the project on a site that is not exposed to any disaster like floodplain.

II. Credit Points for sustainable site

1. Developed Areas: Credit points are obtainable to locate the project in a developed area that the government started to develop it to conserve natural and financial resources required for construction and maintenance of infrastructure.

2. Reduced Automobile Dependence: Cred it points are obtainable to locate the project on a site which is connected to public transportation. At least half of units are within a 400 meters walk distance to bus stations, or within a 800 meters walk distance to rail stations [3].

3. Bicycle Network: Credit points are obtainable to provide an existing bicycle network and if the project is residential, the bicycle network must be connected to schools and facilities [4].

4. Habi tat andW ater Conservation:

a.Do not disturb natural habitat around the project.

b.Design the project to conserve all water bodies in the site.

c.Provide a long-term management plan (ten years) for the habitats and water bodies in the site.

\subsection{Category 2: Neighborhood Pattern}

\section{A. Objectives:}

- Reduce car dependence and encourage walking and cycling.

- Encourage projects those are well connected to the community.

B. Details of credit points in categ ory 2: 


\section{Mandatory Minimum Requirements}

M.1 Trans portation Efficiency: Credit points are obtainable to achieve all of the following:

a. The neighborhood must have $90 \%$ of units face a public space (street, square, garden) and connected to sidewalks.

b.Provide a resting place every $350 \mathrm{~m}$ along all primary walkways which must be totally shaded [5].

c.Provide walking sidewalks on streets with 2.5 meters wide at least [3].

M.2 Compact Development Density: Cred it points are obtainable to provide density calculations include all planned and existing build ings within the project.

II. Credit Points for Neighborhood Pattern

1. Walkable Streets: A project may earn a maximum of 12 points as listed in Table 4:

Table 4: Points for walkable streets [3].

\begin{tabular}{|c|c|}
\hline Detailed point & Points \\
\hline \multicolumn{2}{|l|}{ Building entrances } \\
\hline $\begin{array}{l}\text { 1. At least } 80 \% \text { of the total street-facing building } \\
\text { facades is no more than } 7.5 \mathrm{~m} \text { from the property line. }\end{array}$ & 1 \\
\hline $\begin{array}{l}\text { 2. At least } 50 \% \text { of the total street-facing building } \\
\text { façades is no more than } 5.5 \mathrm{~m} \text { from the property line. }\end{array}$ & 1 \\
\hline $\begin{array}{l}\text { 3. At least } 50 \% \text { of the mixed-use and nonresidential } \\
\text { street-facing build ing façades in the project is within } \\
30 \mathrm{~cm} \text { of a sidewalk. }\end{array}$ & 1 \\
\hline \multicolumn{2}{|l|}{ Ground-Level Use and parking } \\
\hline $\begin{array}{l}\text { 4. In mixed-use projects, all mixed-use buildings } \\
\text { must include ground floor (retail, live-work spaces, } \\
\text { or ground-floor dwelling units) along at least } 60 \% \text { of } \\
\text { the street-level interface; and at least half of office } \\
\text { buildings must include ground floor retail along } 60 \% \\
\text { of the length of the street-level interface. And all } \\
\text { community services on the ground floor must be } \\
\text { accessible directly from sidewalks along a public } \\
\text { space such as a street, square, or plaza, but not a } \\
\text { parking lot. }\end{array}$ & 1 \\
\hline $\begin{array}{l}\text { 5. The ground floor residential units must have an } \\
\text { elevated finished floor at least } 60 \mathrm{~cm} \text { above the } \\
\text { sidewalk surface. }\end{array}$ & 1 \\
\hline $\begin{array}{l}\text { 6. Any ground-level windows must be kept visible at } \\
\text { night in retail and services spaces. }\end{array}$ & 1 \\
\hline $\begin{array}{l}\text { 7. On street parking is provided on a minimum of } \\
70 \% \text { of both sides of all streets. }\end{array}$ & 1 \\
\hline $\begin{array}{l}\text { 8. Provide sidewalks along both sides of all streets } \\
\text { and must be at least } 3 \text { meters wide on retail or mixed- } \\
\text { use blocks and at least } 1.5 \text { meters wide on all other } \\
\text { blocks. }\end{array}$ & 1 \\
\hline $\begin{array}{l}\text { 9. At least } 40 \% \text { of all street frontages within the } \\
\text { project have a minimum building height to street } \\
\text { width ratio of } 1: 3 \text {. }\end{array}$ & 1 \\
\hline \multicolumn{2}{|l|}{ Design Speeds for safe walking and bicy cle travel } \\
\hline $\begin{array}{l}\text { 10. } 75 \% \text { of residential-only streets within the } \\
\text { project are designed for a target speed of no more } \\
\text { than } 20 \mathrm{mph} \text {. }\end{array}$ & 1 \\
\hline $\begin{array}{l}\text { 11. } 70 \% \text { of nonresidential and/or mixed-use streets } \\
\text { are designed for a target speed of } 25 \mathrm{mph} \text {. }\end{array}$ & 1 \\
\hline \multicolumn{2}{|l|}{ Sidewalk intrusions } \\
\hline $\begin{array}{l}\text { 12. Sidewalks do not cross with driveways more } \\
\text { than } 10 \% \text { of the length of sidewalks within the } \\
\text { project. }\end{array}$ & 1 \\
\hline
\end{tabular}

2. Mixed-Income Diverse Communities: Cred it points are obtainable to include a sufficient variety of housing sizes and types in the project.

3. Compact Development: Credit points are obtainable to build residential components at the following densities [3]:

a.Separated (or semi separated) residential building for one family 5-8 units per acre.

b.Separated residential building for two families 10-12 un its per acre.

c.Connected (or semi separated) residential building for one family 16-19 units per acre.

d.Apartment building from 3 stores 40-44 units per acre.

e.Apartment building from 5 stores 70-75 units per acre.

f. Apartment building from 7 stores $75-87$ units per acre.

g.Apartment building from 10 stores 100-108 units per acre.

4. Mixed-Use Neighborhood Centers: The neighborhood center must have 400 meters walking distance from the core to all units as shown in Figure 3. The center also must contain[6]:

a. Retail like books and clothes shops.

b.Professional office like medical facilities.

c.Personal services like salon.

d.Eating and drinking places.

e.Entertain ment and culture facilities.

f. Public facilities like Scholes and library. g.Re ligious facilities.

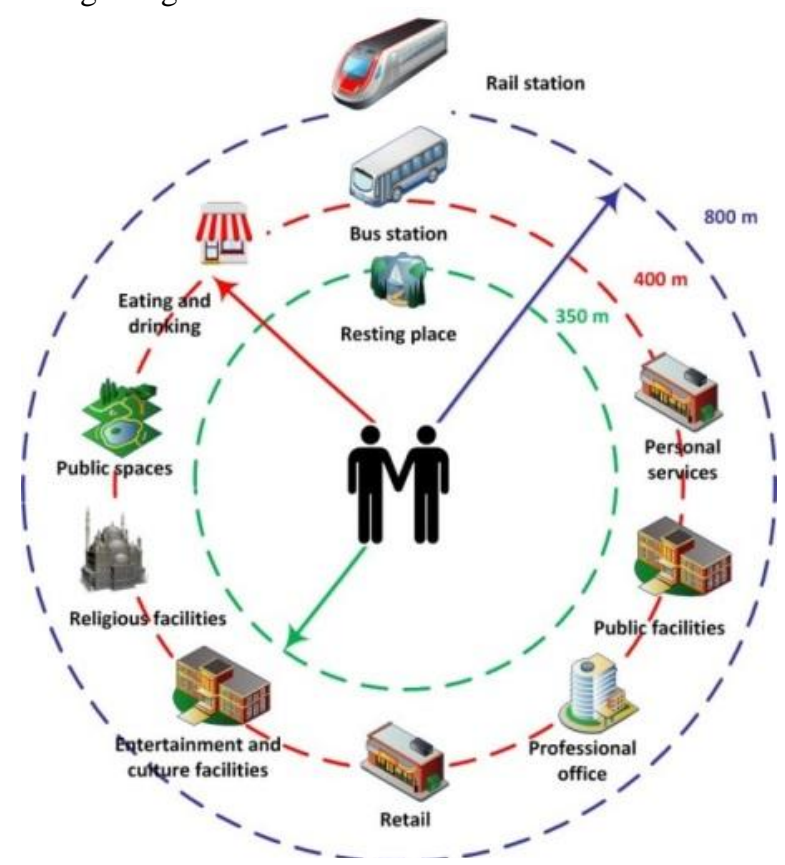

Figure 3: Walking distances to facilities and neighbor hood center

\section{Tree-Lined and Shaded Streets:}

a.Tree-Lined Streets: the streets must be connected and have gradual widths. 
b.Shaded Streets: $40 \%$ of the streets must be shades by trees or other devices.

6. Community Outreach and Involvement: Credit points are obtainable to make an open community meeting to design the project on the citizens needs.

7. Street Network:Design the project such that its width of streets as shown in Table 5.

Table 5:Supposed streets width [3].

\begin{tabular}{|l|l|}
\hline \multicolumn{1}{|c|}{ Type of street } & \multicolumn{1}{c|}{ Width with meters } \\
\hline Local streets & $8-10 \mathrm{~m}$ \\
\hline Collector streets & More than $12 \mathrm{~m}$ \\
\hline Main streets & More than $16 \mathrm{~m}$ \\
\hline
\end{tabular}

8. Access to Civic and Public Spaces: Cred it points are obtainable for designing public spaces (square, park, or plaza) within 800 meters walk distance from units entrances.

9. Reduced Parking Footprint: Credit points are obtainable for:

a.Interfaces of multiunit residential building must be free of parking lots.

b.Using underground or multistory parking buildings to provide parking areas so that the street parking areas do not be more than $20 \%$ of the total development footprint area[3].

c.Providing bicycle parking to all buildings.

10. Neighborhood Schools and playground: The areas must be as shown in

11. Table 6 :

Table 6: Neighborhood schools and playground [7]

\begin{tabular}{|c|c|}
\hline Primary schools & 5 acres \\
\hline Middle schools & $\begin{array}{c}10 \text { acres (serve more than one } \\
\text { neighborhood) }\end{array}$ \\
\hline High schools & (More neighborhoods). \\
\hline Playground & 4 acres \\
\hline
\end{tabular}

And the walk distance to the primary schools must not exceed 400-800 meters [7].

\subsection{Category 3: Sustainable Buildings and Infrastructure}

\section{A. Objectives:}

- Encourage designing sustainable buildings.

- Encourage designing energy-efficient buildings those reduce air, water, and land pollution.

- Encourage the development of energy-efficient neighborhoods.

- Reduce adverse environmental effects from energy used for operating public in frastructure.

B. Details of cre dit points in categ ory 3:

I. Mandatory Minimum Requirements

M.1 Certified Green Building: Design and construct, every building within the project to be certified through GPRS.

\section{M.2 Minimum Building Energy}

Efficiency:Develop and integrate a comprehensive energy strategy which should include[8]: a. Prediction of energy consumption and emissions by an approved energy modeling software. This should include:

- Heating, cooling and electricity demand.

- Emissions from both planned and unplanned energy use.

- Emissions from with street lighting.

b. Recommendations for future reducing in energy use through:

- Site layout

- Use of topography

- Shading

- Solar orientation

- Use of daylighting

- Wind management

- Use of natural ventilation.

c. Recommendations for future reducing in $\mathrm{co}^{2}$ emissions.

M.3 Minimum Building Water Efficiency: Develop and integrate a comprehensive water strategy during the early stages of design to minimize the overall water consumption and establishing aproject water balance [5].

M.4 Construction Activity Pollution Prevention: Cred it points are obtainable for modify ing noise and exhaust emissions from equip ment on Site.

II. Credit Points for Sustainable Buildings and Infrastructure

1. Indoor water Efficiency Improvement: Maximum 2 credit points are obtainable for providing:

a.Completed Community Water Calculator detailing the output of the community water balance.

b.Specify the used water saving devices.

2. Outer Water Efficiency Improvement: Cred it points are obtainable for demonstrating that:

a.Completed Community Water Calculator confirming the landscape requirements will be achieved.

b.Site plan showing landscaped areas, highlighting areas of hardscape and soft cape, as well as water swimming pool areas.

c.Calculations detailing how the total annual average irrigation demands of external soft cape areas (liters/day) is determined as [5]:

- All public park landscaping in aggregate does not require more than $10 \mathrm{l} / \mathrm{m}^{2} /$ day;

- All streetscape landscaping in aggregate does not require more than $71 / \mathrm{m}^{2} /$ day;

- All remaining landscaping in aggregate does not exceed $4 \mathrm{l} / \mathrm{m}^{2} /$ day.

- Plant schedules for the development's landscape program that includes the following key data: Plant names and Annual water de mand.

3. Waste Water Management: Cred it points are obtainable for demonstrating that: 
a.Using of non-potable water (captured rainwater, or recycled grey water for build ing sewage and irrigation).

b.Prevent entering un-treated water to the local environment and provide supporting documentation which includes: drawings of the proposed systems and calculations, specifications and data sheets.

c. The reused treated waste water generation quality must be acceptable with the standards of the Egyptian environmental laws.

4. Certified Green Buildings: Credit points are obtainable for designing a percentage of the total project building square footage, beyond the requirement to be certified under GPRS as summarized in Table 7.

Table 7: Points for green buil ding certification Percentage of square footage certified

$\geq 10 \%$ and $<30 \%$
$\geq 30 \%$ and $<50 \%$
$\geq 50 \%$

5. Energy Efficiency Improvement: Maximum 2 credit points are obtainable for demonstrating further reductions in energy consumption from a base case building. Points awarded are accumulative as shown in Table 8:

Table 8: Points for Energy Efficiency Improvement Percentage of Energy Efficiency Improvement Points From 5\% to $25 \%$ Above 25\%

6. On-site Renewable Energy Sources: Cred it points are obtainable for demonstrating that:

a.An on-site or off-site renewable energy feasibility study has been undertaken.

b.Energy demand of the project must be supplied through renewable energy, using on-site or offsite sources.

c.Points are calculated as shown in Table 9:

Table 9: Points for On-site Renewable Energy Sources

\begin{tabular}{|c|c|}
\hline $\begin{array}{c}\text { Percentage of On-site Renewable Energy } \\
\text { Sources }\end{array}$ & Points \\
\hline From 5\% to 25\% & 1 \\
\hline Above 25\% & 2 \\
\hline
\end{tabular}

7. Infrastructure Energy Efficiency: Install all infrastructure, (traffic lights, street lights, and water and wastewater pumps) which achieve an annual energy reduction less than an estimated baseline energy use for this infrastructure by $15 \%$ [3].

8. Neighborhood Heating and Cooling:Install district heating and cooling system for space conditioning and water heating supply at least $80 \%$ of the project's annual heating and cooling consumption.
9. Energy Micro grid system Install Smart grid management system (Demand response systems) that automate, monitor and control two-way flows of energy from power plant to plug.

10. Solar Orientation: At least $75 \%$ of the buildings must have longer axis (at least 1.5 times length of other axis), which is to east-west with an angle \pm 30 degrees [3] as shown in Figure 4.

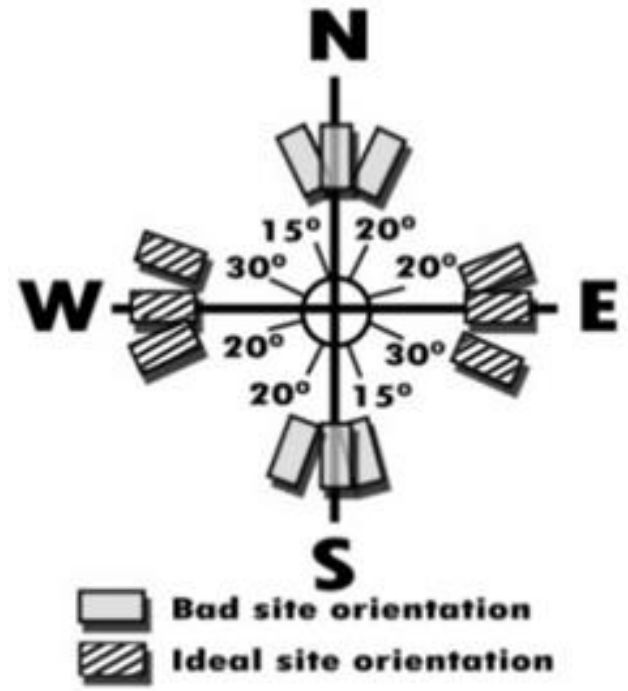

Figure 4: Solar-oriented buildings

\section{Urban Heat Reduction}

a.Nonroof surfaces: Demonstrate that $70 \%$ of community hardscape areas excluding roads are using materials with a minimum Solar Reflective Index (SRI) of 29[5].

b.Green roofs: The roof area of all buildings within the project must have roofing materials with a SRI equal to or more than 29[5], or plant a vegetated roof for at least $50 \%$ of the roof area of all buildings [3].

12. Optimized Ventilation: Credit points are obtainable for providing $\mathrm{CO}^{2}$ monitoring system within the building which alerting residents when additional fresh air is required. And $\mathrm{CO}^{2}$ levels must not exceed 1000ppm[9].

13. Thermal Comfort: Cred it points are obtainable for providing heating and cooling demands for all spaces within the building.

14. Visual and Acoustic Comfort : Cred it points are obtainable for:

a.All units must have the suitable lighting intensity to meet the required applications; and must have automatic controls for energy saving with the analyses for compromising between day-lighting and artificial lighting.

b.In public areas, install automatic controls that turn off exterior lighting when sufficient daylight is available.

c.In residential areas, at least $50 \%$ of the external lightings must have motion sensors to reduce 
light levels by at least $50 \%$ when no activity has been detected for 15 minutes [3].

d.All spaces must be determined suitable acoustic conditions and noise control strategies, all in accordance with national codes.

15. Regional and Recycled Materials : credit points are obtainable for:

a.Demonstrate that building materials are extracted and manufactured in Egypt. The value of regional materials must be more than $20 \%$ of total materials [10].

b.Recycled renewable. The Recycled materials must be more than $15 \%$ of total materials which include earth materials, natural stone, palm tree products, bamboo, wool and cotton for insulation [5].

16. Solid Waste Management Infrastructure: Cred it points are obtainable for meeting at least four of the following five require ments [3].

a.Provide at least one waste recycling station, accessible to all project occupants, and the materials must be separated to paper, glass, plastics, corrugated cardboard, and metals.

b.Provide at least one drop-off point for potentially hazardous office or household wastes like paints, solvents, oil, and batteries.

c.Provide at least one compost station to collect food and yard wastes.

d.Provide recycling containers in every residential block.

e.Provide a construction waste management plan that explains the materials transportation from disposal and the storage of materials.

17. Minimizing Pollution During Construction: A credit point is obtainable for providing a strategy to minimize pollution from construction operations (including generation of dust and pollutants ) [10]

18. Respect for Sites of Historic or Cultural Interest: A credit point is obtainable for providing a suitable strategy for protecting his toric or cultural places in the site.

\subsection{Category 4: Innovation and Design Process}

\section{A. Objectives:}

- Design initiatives and construction practice which have a significant measurable environmental benefits.

- Give an attention to national traditions in design and resect privacy.

B. Details of credit points in categ ory 4:

I. Mandatory Minimum Requirements

There is no Mandatory Minimu m Requirements.

II. Credit Points for Innovation and Design Process

1.Innovation: Credit points are obtainable for innovative design or construction practices which have a significant measurable environmental benefit and which are not otherwise awarded points by GPRS.
2. Cultural Heritage: Cred it points are obtainable for including architectural, construction and technical solutions which reflect national and regional cultural heritage while contributing to the environmental performance of the building.

\section{RESULTS AND DISCUSSIONS}

From the proposed rating system the whole neighborhood can be evaluated. It gives credits to site selection, design, and construction elements that bring buildings and infrastructure together into a neighborhood. Also it relates the neighborhood to its landscape as well as its local and regional context. On the other hand it deals with the energy grid supply to achieve zero net energy consumption and zero carbon emissions annually. As a result, designers must deal with neighborhoods with those four categories to establish a clean energy neighborhood. The weights of the categories of GPNRS are shown in Figure 5.
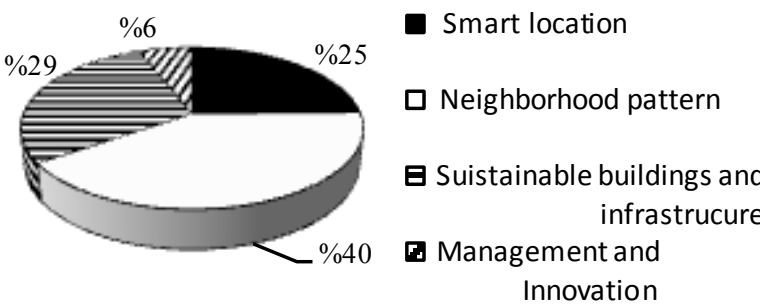

Figure 5: Proposed Green Pyramid

Neighbourhood Rating System categ ories weight

Comparison between LEED for neighborhood development and proposed GPNRS for clean energy neighborhood is shown in Figure 6.

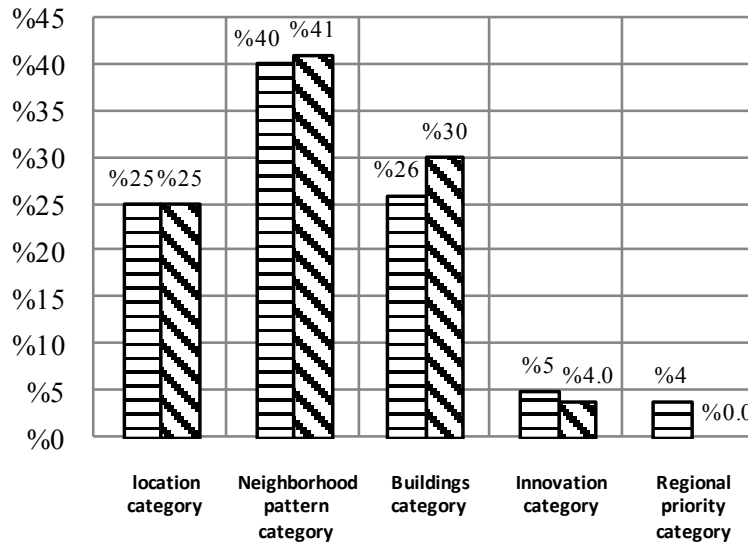

$\square$ Leadership in Energy and Envirnomental Design for Neighborhood Development

$\boldsymbol{\nabla}$ Proposed Green Pyramid Neighbourhood Rating System

Figure 6: Comparison between Leadershipin Energy and Envirnomental Design for Neighborhood De velopment and Green Pyramid Nieghborhood Rating System. 
Figure 6 shows that:

1. The proposed rating system gives a big attention to the sustainable buildings and infrastructure category because it is a new concept in Egypt.

2. There isn't a region priority category in GPNRS for clean energy neighborhood because it is included in management and innovation category which has a low weight like in GPRS.

3. Sustainable buildings and infrastructure category has a higher weight in GPNRS because it includes water and energy sub category which is important to Egypt nowadays.

\section{CONCLUSIONS}

The proposed rating system develops the GPRS to deal with a neighborhood scale. It deals with the neighborhood with all its components to make sure that every item will reduce energy consumption and achieve sustainability. Also to connect all elements together to create a neighborhood that efficiency uses the energy produces from renewable energy resources.

\section{REFERENCES}

[1] Sharifi, A., \& Murayama, A., 2012: A critical review of seven selected neighborhood sustainability assessment tools. Environmental Impact Assessment Review, vol. 38, 73-87 pp.
[2] Haapio, A. (2012). Towards sustainable urban communities. Environmental Impact Assessment Review, vol. 32(1), 165-169 pp.

[3] Congress for the New Urbanis m, Natural Resources Defense Council, and the U.S. Green Building Council, 2009: LEED 2009 for Neighborhood Development Rating System, United States.

[4] Rudlin D., and Falk N., 2012: Sustainable Urban Neighborhood: Building the Twenty-first Century Ho me, Routledge, United Kingdom.

[5] Abu Dhabi urban planning council, 2010: The Pearl Rating System for Estidama Community Rating System Design and Construction.

[6] R. S. Frederick, and Butler K. 2012: Planning and Urban Design Standards, American Planning Association, John Wiley and Sons, New Jersey, 231 pp.

[7] Alam A. K. 1998: Cities Planning, Egyptian Anglo bookstore, Cairo.

[8] UK Accreditation Service, 2012: BREEAM Communities Technical manual, United Kingdom, 23 pp.

[9] Block M., and Bokalders V.,2013: The Whole Building Handbook: How to Design Healthy, Efficient and Sustainable Buildings,Earthscan, London, $117 \mathrm{pp}$.

[10] Ministry of Housing, The Housing and Building National Research Center, and The Egyptian Green Building Council, 2011: The Green Pyramid Rating System First Edition, Cairo. 